Estudios de la Paz y el Conflicto

Revista Latinoamericana

IUDPAS-UNAH

Volumen 1, Número 2, pp. 150-161

ISSN-e: 2707-8922 / ISSN: 2707-8914

DOI: $10.5377 /$ rlpc.v1i2.9838

Julio-diciembre 2020

\title{
COVID-19: LA SOCIEDAD CAUTIVA EN EL ESPACIO GLOBAL
}

\author{
COVID-19: THE CAPTIVE SOCIETY IN THE GLOBAL SPACE
}

\author{
Marina Inés de la Torre \\ Universidad de Guanajuato \\ marinadlt8@hotmail.com
}

Recibido: 12-03-2020

Aceptado: $13-04-2020$

Cómo citar / citation

De la Torre, M. (2020). "Covid-19: La sociedad cautiva en el espacio global", Estudios de la Paz y el Conflicto, Revista Latinoamericana, Volumen 1, Número 2, 150-161. DOI:

10.5377/rlpc.v1i2.9838

\begin{abstract}
Resumen
Nuestra sociedad globalizada exhibe sin pudor la amenaza potencial a su especie. La difusión descontrolada de una enfermedad sin precedentes: el COVID-19, está produciendo consecuencias para el desarrollo humano aún imposible de prever. Percepciones y realidades de un fenómeno reciente en plena expansión. Una nueva afrenta que provoca y desquicia a la sociedad en su conjunto. En suma, un espectáculo dantesco digno de la pluma de Saramago. ¿Cuáles son las condiciones de contexto y las acciones implementadas? ¿Qué nuevos retos asume el espacio urbano? ¿Qué riesgos y oportunidades anuncia? ¿Qué ocurre en los espacios de frontera? La respuesta a dichos interrogantes tiene como propósito reflexionar teóricamente en torno a la dimensión espacial de este coronavirus, y su impacto en la sociedad humana. Cabe mencionar el carácter provisional y tentativo del presente ensayo, habida cuenta de la vigencia temporal y espacial del proceso que se intenta abordar.
\end{abstract}

\section{Palabras clave}

Pandemia; coronavirus; espacio; sociedad.

\section{Abstract}

Our globalized society unashamedly displays the potential threat to its species. The uncontrolled spread of an unprecedented disease: COVID-19, is producing consequences for human development that are still impossible to foresee. Perceptions and realities of a 
recent phenomenon in full expansion. A new affront that provokes and drives society as a whole. In short, a dantesque show worthy of Saramago pen. What are the context conditions and the actions implemented? What new challenges does the urban space assume? What risks and opportunities does it announce? What happens in the border spaces? The answer to these questions is intended to reflect theoretically on the spatial dimension of this coronavirus, and its impact on human society. It is worth mentioning the provisional and tentative nature of this essay, given the temporal and spatial validity of the process that is being attempted.

\section{Keywords}

Pandemic; coronavirus; space; society.

\section{EN TORNO AL CONCEPTO DE RIESGO}

Hoy más que antes, viene a la mente el recuerdo de la sociedad del riesgo, del pensador alemán Ulrich Beck (2006), influyente intelectual contemporáneo.

La sociedad del riesgo, identifica un conjunto de miedos sociales, tales como desempleo, pobreza, enfermedad, entre otros, vinculando el fenómeno con los cambios estructurales de la modernidad tardía.

"Los riesgos despliegan dentro de su radio de acción y entre los afectados por ellos un efecto igualador. Ahí reside precisamente su novedosa fuerza política (...)”, “(...) las sociedades del riesgo no son sociedades de clases, sus situaciones de peligro no se pueden pensar como situaciones de clases, ni sus conflictos, como conflictos de clases" (Beck, 2006: 52).

"El discurso del riesgo empieza donde la confianza en nuestra seguridad termina...", expresa Ulrich Beck (2006: 56). La crisis de la modernidad, caracterizada por la búsqueda de dominio y de control, ha transformado las relaciones entre la sociedad y el Estado (fin del Estado de bienestar como garante de la seguridad social), y entre la sociedad y la naturaleza (a través de la toma de conciencia de los riesgos ambientales) (Beck, 2006).

Castel (2013) propone una reflexión crítica respecto a la inflación de la noción de riesgo, que conduce a pensar la sociedad actual como una sociedad de riesgo. En tal sentido, nos dice el autor, es importante distinguir y caracterizar los diferentes tipos de riesgos, y las maneras específicas de afrontar y combatir cada uno de ellos. Dado que cada riesgo suscita un sentimiento de inseguridad particular, el autor confirma una relación de convergencia entre inseguridad y riesgo e identifica tres tipos de riesgos (cuyo orden alteraremos en función de los intereses del presente estudio): a) riesgos sociales, b) población de riesgo y, c) riesgos ecológicos. A cada tipo de riesgo le corresponde la movilización de diferentes medios para ser combatidos, a saber:

Los primeros, generan un estado de indefensión y desamparo en la población. Están comprendidos por accidentes, enfermedades, desempleo, pobreza, entre muchos otros, y demandan la intervención del estado nacional para su atención.

En segundo lugar, la abstracción del problema en términos de una realidad en riesgo constante, conduce a un estado de inseguridad general e indeterminado donde, el concepto de población de riesgo, surge como una estrategia posible que permite simplificar la complejidad del fenómeno, orientada a la circunscripción del problema a un segmento de Estudios de la Paz y el Conflicto, Revista Latinoamericana, IUDPAS-UNAH, Volumen 1, Número 2, julio-diciembre 2020, pp. 150-161. DOI: $10.5377 /$ rlpc.v1i2.9838 
población. De este modo, se alude a los factores de riesgo que presentan algunos individuos o grupos sociales, los cuales reúnen características comunes que los convierten en potencialmente peligrosos para el resto del colectivo social, identificando el problema con poblaciones socialmente vulnerables. La emergencia de una nueva modalidad de gestión de estas poblaciones sugiere inquietantes, cuando no peligrosas, estrategias de vigilancia y de control.

Por último, la amenaza a la especie humana, producida por la omnipresencia de los riesgos ambientales sugiere un incremento del estado de inseguridad, cuya instrumentación requiere de acuerdos internacionales de control del crecimiento económico a expensas de los recursos naturales.

Que haya riesgos significa que el futuro es aleatorio, y, en tal sentido, portador de una amenaza. Cuantos más riesgos hay, más aumenta el sentimiento de inseguridad.

Ahora bien, aceptando que el miedo o inseguridad ocupa un importante lugar en el pensamiento social, hay quienes lo juzgan de modo negativo, criticando a los medios, a los políticos y también a los intelectuales, por presentar de manera sensacionalista un conjunto de problemas sociales que provocan paranoia en la sociedad. En contraste, otros enunciados rescatan el valor positivo del miedo, el cual alimenta una permanente actitud de vigilia frente a la omnipotente tentación de opresión por parte del Estado (Kessler, 2009).

\section{PANDEMIA: PERCEPCIONES Y REALIDADES}

El miedo en cuanto tal, es una emoción, un sentimiento en el que convergen una diversa gama de desasosiegos. A la luz de la emergencia actual, se trata del miedo al contagio, a la pérdida de la salud, a la indefensión ante los embates de la enfermedad.

Sin embargo, hechos y percepciones están lejos de tener una correspondencia unívoca. Los hechos están cuantificados en las estadísticas que dan cuenta de la cantidad de personas afectadas por el virus o sospechosas de poder estarlo, las cuales se actualizan en tiempo real (en el mejor de los escenarios). La percepción en cambio, consiste en la interpretación subjetiva, ya sea individual y/o colectiva, de esa realidad fáctica. Es decir que el miedo, puede seguir en ascenso, a la vez que la expansión del contagio disminuye y, viceversa.

Esta divergencia entre ambos conceptos, ha dado lugar a un conjunto de hipótesis y teorías que intentan explicar los procesos que median entre los hechos y las emociones, y constituye la marca de origen del problema y su mayor interés de observación (Kessler, 2009). En este sentido, suele ser la base para cuestionar la irracionalidad de los miedos y de toda política pública basada en ellos.

Lo cierto es que, el estado de precariedad que el miedo produce en la población, requiere de políticas sociales inmediatas, instrumentadas desde el Estado. Las estrategias de control tendientes a evitar el pánico generalizado en la población, constituyen hoy un desafío tan importante como el imperativo de desarrollar estrategias para evitar la expansión de la enfermedad misma. 


\section{COSMOPOLITISMO Y DERECHO A LA SEGURIDAD}

La idea clásica del Estado-nación, como unidad geográfica de una sociedad relativamente homogénea, se ha visto cuestionado por los movimientos migratorios tanto externos como internos y un evidente multiculturalismo. Dichos cambios nos enfrentan a la necesidad de ampliar sus confines conceptuales.

Ahora bien, el concepto de cosmopolitismo es complejo y polisémico y requiere ser entendido desde las múltiples perspectivas del conocimiento, propósito que escapa al alcance del presente ensayo. En reglas generales, se trata de un fenómeno asociado a las prácticas neoliberales de la economía global, que tiene como consecuencia una intensa movilidad humana mundial. En tal sentido, el fundamento y razón del cosmopolitismo refieren a la capacidad de gestionar las diferencias culturales de una sociedad heterogénea portadora de múltiples sistemas identitarios, donde el derecho individual de carácter universal confronta al derecho de las comunidades localizadas, aportando nuevas complejidades entre las aspiraciones globales y la autodeterminación local. Todo ello impacta en la estructura de los colectivos sociales y en la configuración de sus respectivos territorios.

Ulrich Beck (citado por D. Harvey, 2017), advierte en relación a un cambio de paradigma a partir del cual, el principio del derecho internacional, cede el paso a los derechos humanos universales. Los sujetos de derechos humanos pasan a ser los individuos, ya no los sujetos colectivos como pueblo o Estado. Ello nos refiere, a la universalidad de los derechos humanos individuales y a una lógica que trasciende las fronteras nacionales.

Este contexto argumental, permite especular en relación al comportamiento desigual de los estados nacionales para asegurar el derecho a la protección de sus ciudadanos frente a la emergencia global. Dicho comportamiento requiere ser interpretado y confrontado a la luz de las particulares condiciones de contexto de cada nación.

\section{ACCIONES Y REACCIONES EN EL ESPACIO LOCAL}

Como es de dominio público, la aparición del COVID-19 en humanos, se detecta por primera vez en China. Al igual que sucede en otros países asiáticos, la República Popular China, se caracteriza por un capitalismo de Estado de carácter totalitario en el que, gobierno y Estado se identifican y convergen en un sólo partido, el partido comunista.

La gestión de la crisis sanitaria es sin lugar a dudas, de naturaleza política y en ella se refleja no sólo el instinto, sino también, el músculo autoritario característico de China (Fantini, 2020). La opacidad con la que administra la información en un comienzo, acallando a los propios médicos que sonaron la alama por primera vez, contrasta con la eficacia reactiva para hacer frente a la emergencia, después. Una vez que el Estado resuelve dar a conocer públicamente la situación y evalúa sus consecuencias para la nación y el mundo, despliega una incontestable capacidad para administrar la crisis, en la que destacan la celeridad y la escala de sus intervenciones. Esta capacidad de respuesta está directamente asociada a una mayor concentración del poder.

En las democracias occidentales las dinámicas de gestión de la crisis están resultando diferente. La clave para su comprensión, es posible encontrarla en la existencia de escenarios de libertad más amplios, los cuales admiten márgenes de negligencia por parte de gobiernos y gobernados. La primera refiere a la reticencia de los gobiernos a tomar medidas 
impopulares, que pudieran empañar el futuro de sus respectivas administraciones. La segunda, refiere a la indolencia de la población al momento de tomar sus reasuguros, ya que todos estamos supuestamente informados. "Amor con amor se paga", reza el dicho popular. El ejercicio de la libertad obliga a asumir mayores responsabilidades que vayan más allá de la espera de consignas por parte de un Estado paternalista.

En general, la transparencia de la información pública en las democracias (sin entrar a considerar su calidad), ha sido una constante desde el comienzo. Sin embargo, la falta de celeridad y rezago en la toma de medidas de control, empieza a causar estragos en algunos países como Italia. Europa ha estado siempre en mejores condiciones que China para enfrentar la crisis ya que, al igual que América, ha dispuesto y dispone de tiempo. Ese tiempo necesario para tomar medidas preventivas, ya no para evitar la expansión de la enfermedad, posibilidad cada vez más alejada en el espacio global, sino para gestionar protocolos eficientes que ayuden a mitigarla.

Esta situación pone en evidencia la ineficacia de los sistemas democráticos en épocas de crisis, donde la variable temporal es clave y, en tal sentido, las medidas que llegan a destiempo resultan equivalentes a una ausencia de medidas.

\section{ESPACIOS DE CLAUSURA}

Dentro del vasto universo conceptual de Foucault, la heterotopía se revela como el concepto más idóneo para comprender la naturaleza de los espacios de clausura.

La heterotopía consiste, expresa el autor en el estudio de "esos espacios absolutamente otros". Del enunciado de los cinco principios fundamentales Foucault, es preciso detenerse en el quinto, a saber, los "sistemas de cierre y apertura específicos".

En dichos sistemas el autor distingue tres tipos heterotópicos:

El primero se refiere a "[...] las heterotopías tienen siempre un sistema de apertura y cierre que las aísla del espacio que las rodea [...]” (Foucault, 2008: 59).

El segundo refiere a que "[...] Hay otras heterotopías, por el contrario, que no están cerradas en relación al mundo exterior, pero que son pura y simple apertura [...]" (Ibid). En este caso la heterotopía es un lugar abierto en el que, una vez que se ingresa, descubre que se sigue quedando fuera, y es ejemplificada por el autor, con los visitantes de paso.

El tercero "[...] Finalmente, existen las heterotopías que parecen abiertas, pero en las que sólo entran verdaderamente los que ya han sido iniciados [...]" (Ibid).

Estas heterotopías expresan las ambigüedades espaciales de los espacios de clausura en los cuales se vive la ilusión de un futuro que pocas veces conquista. La condición liminar de estos espacios encuentra aquí su mayor expresión, a través de dos vías de impugnación. Creando una ilusión que denuncia al resto de los espacios reales o, creando nuevos espacios en franca oposición a los reales. Espacios éstos que resultan tan perfectos como cerrados en su organización, similares a un barco navegando en el océano.

Ahora bien, la dinámica de cambio acelerado que imprime al espacio la expansión de la enfermedad involucra progresivamente no sólo al conjunto de heterotopías sino a todos los grupos sociales.

Individuos, grupos minoritarios de población, ciudades hasta naciones enteras, reproducen las múltiples escalas de la clausura. 
Las condiciones de accesibilidad en las fronteras nacionales dependen de las decisiones que al respecto se producen al interior de cada una de las administraciones locales, y en tal sentido, sus alcances son distintivos.

La presencia de fronteras poco porosas, no sólo predomina en el actual contexto mundial, sino que, tiene una antigua data. Se trata de la mayor o menor restricción, cuando no prohibición de paso, dirigida a los migrantes que se desplazan de sus lugares de origen (por diversas causas), en busca de otros destinos "de acogida". Ello contrasta con el derecho a la libre circulación (entrar y salir) con el que se ve beneficiado el connacional.

Ahora bien, a la luz de la nueva emergencia sanitaria, el cierre de las fronteras aplica, no sólo para los foráneos, sino también para los connacionales, y esto constituye toda una novedad en la que, el cierre aísla a los de adentro y excluye a los de afuera.

Las intenciones humanitarias de estas acciones en apariencia extremas, no dejan lugar a dudas, ya que constituyen verdaderas acciones de paz que reivindican el derecho universal a la protección frente a la contingencia.

Más cuestionables resultan las intenciones de mantener fronteras porosas sólo en un sentido, las cuales privilegian el derecho de las ciudadanías locales a la libre circulación, poniendo en riesgo la integridad de las ciudadanías ajenas.

Las estrategias de contención de la emergencia se dirimen en mundos paralelos (global y locales) no siempre convergentes, manifiesta en las condiciones de desigual accesibilidad a los espacios fronterizos.

\section{DINÁMICAS ESPACIALES ESTIGMATIZANTES}

Goffman (1970) define al estigma como "[...] una clase especial de relación entre atributo y estereotipo [...]" (1970: 2). El autor señala que, cuando el/los atributo/s discrepan de las expectativas generadas por el grupo social de pertenencia (estereoptivo), el individuo o colectivo es percibido fuera de la "normalidad". En tal sentido, la variabilidad de un atributo es evidente, ya que las expectativas se corresponden con los valores y marcos institucionales de cada grupo social. Sin embargo, un estigma refiere a un atributo "profundamente desacreditador" para su portador y, en todos los casos, tiene una connotación negativa.

Goffman, introduce la dimensión temporal y distingue las categorías de desacreditables y desacreditados dependiendo del tiempo en el que se acceda al conocimiento del individuo o grupo estigmatizado, siendo portador en mucho de los casos de ambas categorías.

Existen "anormalidades" corporales (discapacitados), comportamentales (enfermos mentales) y tribales, tales como religión (fundamentalismo), nación (chauvinismo), etnia (racismo), y condición socioeconómica (clasismo), todos ellos estereotipos ante las cuales se instrumentan distintas formas de discriminación, sin apreciar que son precisamente estas "anormalidades" las que motivan el desarrollo de nuevas capacidades ausentes en a los "normales".

Sin embargo, la resignación por parte de individuos o colectivos estigmatizados al creer que alguno de sus atributos así lo justifica, conduce a un proceso de creciente autoestigmatización.

La pandemia constituye un riesgo social (Kessler, 2009) que se refiere a la difusión a gran escala de una enfermedad, cuya dinámica espacial avanza sobre el espacio global, implicando 
a su paso a más poblaciones. Su constante dinámica de cambio, no sólo localiza, sino que amplía su escala, se desplaza y se aproxima.

Entrando en el terreno movedizo de los préstamos conceptuales analíticos, resulta temerario identificar a determinados actores sociales (estereotipos) como portadores de la enfermedad (atributo).

Desde que se toma conocimiento del lugar de origen del COVID-19, y a partir de su acelerado proceso de desarrollo, se comienza a ampliar el conjunto de poblaciones estigmatizadas en una clara correspondencia con la expansión territorial. En este caso el estigma está asociado a la salud, es decir a todos aquellos portadores de la enfermedad (desacreditados) o sospechosos de serlo (desacreditables). En un principio se identificó a la población de origen asiático, a la que se suma hoy, la población de procedencia europea. Es cuestión de tiempo para que se amplíe la gama de fenotipos ${ }^{1}$ socialmente indeseables y de territorios prohibidos. Toda vez que se agotan los esfuerzos por asignar atributos estigmatizantes a los otros, se redireccionan hacia el interior del grupo de pertenencia.

Esta dinámica en las percepciones estigmatizantes para afrontar la realidad incierta, contrasta con la permanencia de un estigma consolidado de antigua data. Nos referimos a las poblaciones fronterizas, cuyas ciudadanías precarias, cuando no ausentes, disminuyen ostensiblemente las esperanzas de sobrevivir a la enfermedad, a la que se suma una desesperanza estructural y un creciente desamparo. Son los eternos habitantes del umbral, despojados de derechos y frecuentemente olvidados.

\section{CLAUDICACIONES EN EL ESPACIO TRADICIONAL. NUEVOS ESPACIOS DE CONTAGIO E INMUNIDAD.}

Las nuevas circunstancias exigen una redefinición de los espacios de relación tradicionales.

El espacio público tradicional es un lugar de identificación, de contacto físico entre las personas, de animación urbana y de expresión comunitaria. La difusión de las Nuevas Tecnologías de Información y Comunicación (en adelante, TICs.), han transformado la naturaleza de la interacción social en las sociedades contemporáneas, desarrollando una nueva modalidad de interacción social, a través de estas tecnologías (Thompson, 1998).

En términos de riesgos reales y percibidos por la sociedad en su conjunto, frente a la actual emergencia sanitaria, se propone una nueva categorización, espacios de contagio y espacios de inmunidad.

a. Espacios de contagio: son los espacios tangibles de la proximidad física y constituyen hoy, el espacio de contagio por excelencia. Hoy habitamos un mundo de ciudades prohibidas, en las que la distancia social nos impone el aislamiento.

Bien se sabe que, las relaciones personales, aquellas "cara a cara", son una forma insustituible de relación humana. Ella precisa de un espacio de representación y de una disposición temporal, donde los modestos, casuales y dispersos contactos de proximidad constituyen la base dinámica sobre la cual se sostiene la vida pública en una ciudad.

\footnotetext{
${ }^{1}$ Se denomina fenotipo a la expresión del genotipo en función de un determinado ambiente. Los rasgos fenotípicos cuentan con rasgos tanto físicos como conductuales (del campo de la biología, específicamente en genética).

Estudios de la Paz y el Conflicto, Revista Latinoamericana, IUDPAS-UNAH, Volumen 1, Número 2, julio-diciembre 2020, pp. 150-161. DOI: $10.5377 /$ rlpc.v1i2.9838
} 
Jacobs testimonia: “[...] Las calles y las aceras son los principales espacios públicos de una ciudad, sus órganos más vitales [...]" (1967: 33). La mayoría de los contactos en las calles son ostensiblemente triviales, pero la suma de ellos, no lo es en absoluto. Los encuentros casuales, triviales y públicos a un nivel local, la mayoría de ellos fortuitos y espontáneos entre personas que coinciden en una relación determinada, da como resultado un sentimiento de identidad pública entre las personas, una red y un tejido de respeto mutuo y de confianza, y también una garantía de asistencia mutua para el caso en que la comunidad en general o un vecino en particular, la necesite (Jacobs, 1967). Donde hay confianza aumentan las oportunidades para la experiencia y la acción, en las que la confianza constituye una forma efectiva de reducir la complejidad (Luhmann, 1996).

¿Cómo enfrentar la pérdida temporal de esta posibilidad de enteracción? Las nuevas tecnologías están demostrando ser un sustituto eficaz para contrarrestar la emergencia.

b. El espacio de la inmunidad está asociado al espacio intangible de las nuevas tecnologías de la información y la comunicación, y resulta el más idóneo para evitar el contagio. De él se espera que mantenga articulado el cuerpo social, a través de interactivos circuitos mediáticos que transmiten la información, a la vez que construyen imaginarios sobre la situación actual (De la Torre, 2010). Se fortalece así, el perfil mediático del ciudadano a través del espacio comunicacional, conectividad en la que impera Internet, el cable y la red satelital.

Ahora bien, en el contexto de la actual emergencia sanitaria, el espacio de contagio claudica a favor del espacio de la inmunidad. En otras palabras, los espacios públicos tradicionales, plazas, teatros, cines, ferias y calles residenciales desplazan sus prácticas sociales hacia el espacio comunicacional. En el mismo sentido, García Canclini (2001) afirma que la comunicación inmaterial modifica los vínculos entre lo privado y lo público, los cuales merecen consideración aparte.

La clausura del espacio público tangible, delega sus funciones tradicionales al espacio privado. La vida al interior de los hogares se transforma temporalmente en escenario de relaciones de mayor alcance, intensificando el uso de las redes sociales y el teletrabajo. Se acrecienta el peso de las comunidades virtuales, a través de las cuales se provee de una suerte de inmunidad solidaria para combatir los efectos negativos de un aislamiento involuntario, que impone una "sana distancia social" en la sociedad actual.

En suma, la condición gregaria del habitar humano recrea en forma constante estrategias de comunicación en las que, el espacio privado demuestra estar a la altura de las circunstancias para enfrentar a la adversidad.

\section{PANÓPTICA DEL ESPACIO URBANO}

El estado de emergencia sanitaria tiene consecuencias inmediatas en los hábitos de conducta (cotidianos y cíclicos) de los ciudadanos, quienes implementan acciones tendientes a promover entornos que minimicen riesgos, tanto en el espacio privado, como en el público. Las primeras se relacionan con procesos de autogestión, las segundas refieren a la autocensura, a esta última prestamos atención.

El panopticón se presenta como una buena analogía para entender la situación de una sociedad disciplinaria. Ideada por el pensador inglés Jeremy Bentham en el siglo XVIII, consiste en una estructura carcelaria con celdas distribuidas en forma circular alrededor de 
un centro, en el que se emplaza la torre de control. Esta condición espacial permite asegurar el control centralizado de los reclusos sin que éstos puedan discernir si están o no siendo observados. Implica un proceso de autocensura a través del cual los vigilados modifican su comportamiento por temor a la eventualidad de ser castigados. Se trata de una visibilidad que garantiza el funcionamiento automático del poder, sin que ese poder se esté ejerciendo de manera efectiva.

Más tarde, Foucault (2002) retoma esta idea para denunciar la condición panóptica de la sociedad moderna, la cual se fundamenta en la convicción de que el control induce un comportamiento positivo en los vigilados, basado en el miedo no sólo al castigo, sino dada la situación actual, al contagio de una enfermedad cuyas consecuencias son aún imprevisibles. En este caso la relación entre inseguridad y el riesgo es absolutamente convergente (Castel, 2013).

Las estrategias panópticas se implementan exclusivamente en el espacio público, y atienden las múltiples escalas del problema. El cierre de los espacios comunitarios, urbanos o nacionales exige condiciones de control centralizado y formal por parte de las administraciones locales. Sin embargo, estas estrategias panópticas que todo lo ven, representan la pérdida de libertades, las cuales se ejercen restrictivamente y bajo absoluta vigilancia.

Estrategias de autogestión se instrumentan también en el espacio privado. Son de carácter defensivo y elusivo. Las primeras refieren a aquellas acciones orientadas a la introversión, a definir límites precisos entre lo privado y lo público. La sumatoria de acciones individuales defensivas, determina una relación bipolar público/privado, cuyas fronteras opacas (reales o virtuales) hace evidente una desafección de lo público a favor del espacio privado.

Por último, las estrategias elusivas son comportamentales (Kessler, 2009) y comprenden las acciones tendientes a evitar circular por ciertos lugares considerados de riesgo potencial y restringir salidas en ciertos horarios. Si la percepción del entorno es amenazante, se trata de evadir. Ello impacta negativamente en la construcción de ciudadanía.

La emergencia sanitaria requiere de la implementación simultánea de todas las estrategias disponibles para salvaguardar a la población de los estragos de la enfermedad. Comportamientos elusivos generalizados combinan espacios panópticos y defensivos en la ciudad, dando como resultado el vacío existencial del espacio urbano tradicional.

\section{9. ¿IGUALES ANTE LA ENFERMEDAD?}

Retomando los referentes teóricos de inicio, queda claro que la enfermedad se propaga sin distinción de clase, raza u otra condición, situación que tiene un efecto igualador para el cuerpo social en su conjunto. La enfermedad no solo homologa socialmente, sino también desterritorializa, comprometiendo a la población de cualquier latitud del planeta. En tal sentido, sería una ingenuidad la pretensión de atribuir la enfermedad a ciertos actores sociales o, confinarla a unos límites geográficos aprehensibles.

Sin embargo, las diferencias se hacen notar al interior de las fronteras nacionales, donde la atención de la emergencia depende de los respectivos sistemas de salud. El grado de vulnerabilidad de los grupos sociales está asociado a las reales posibilidades de las administraciones locales para enfrentar con eficacia la emergencia sanitaria. A diferencia de la enfermedad en sí, las posibilidades de su tratamiento, distingue y localiza. 
Ahora bien, la actual crisis mundial, reproduce la paradoja de origen de la globalización planetaria. Las prácticas económicas globales deconstruyen sistemáticamente las fronteras nacionales, al mismo tiempo que los estados nacionales construyen murallas físicas o simbólicas a fin de contener la intensa movilidad humana, a las que la economía global ha contribuido.

En el mismo sentido, la enfermedad no reconoce límites espaciales y se expande profusamente sobre la superficie de todo el planeta, mientras que, el control ejercido por los estados nacionales reconstruye fronteras, con el fin de salvaguardar a propios y, en el mejor de los casos, a ajenos.

Vivimos y pensamos universos paralelos que se complementan y contradicen, se desquician y desbordan para, de vez en cuando, volver a conciliar.

\section{DISCUSIÓN Y CONCLUSIONES}

Las discusiones en torno a un fenómeno en plena expansión no pueden ser concluyentes, ni mucho menos definitivas.

Goffman (1970), Foucault (2008) y Harvey (2017), Saramago ${ }^{2}$ (2005) entre muchos otros, aportan desde la sociología, filosofía, psicología, historia, geografía, antropología y la literatura, miradas concurrentes que dan cuenta de la presencia siempre viva de espacios heterotópicos en el devenir de la existencia humana.

La inédita situación a escala global que hoy se vive, convierte en heterotopías toda la superficie del planeta, instrumentalizando nuevas formas de producción y organización del espacio para adaptarse a las nuevas condiciones de posibilidad de la existencia. Se modifican los clivajes sociales, las demarcaciones espaciales y entre ellas, la porosidad de las fronteras.

La gestión de la emergencia de las administraciones locales oscila entre dos extremos.

Desde un extremo del pleno ejercicio del libre albedrío por parte de los ciudadanos, confiando en su responsabilidad en el cuidado de su propia salud y la ajena. En este caso el Estado se remite a dar recomendaciones y mantiene las libertades individuales en el espacio colectivo.

A otro extremo de imposición de medidas de confinamiento estricto por parte del estado, cuyo cumplimiento es garantizado a través de los controles de seguridad y bajo apercibimiento. El poder central clausura el espacio público en desmedro de las libertades ciudadanas. En este caso es importante recordar la importancia del miedo positivo (Kessler, 2009), que inspira una vigilia ciudadana tendiente a mantener las democracias, resistiendo a la tentación de un estado autoritario a perpetuar las medidas de control más allá de la emergencia declarada y que temporalmente lo justifica.

En discrepancia con Castel (2013), los tiempos de pandemia nos enfrenta sin lugar dudas a una sociedad de riesgo (Beck, 2006) en toda regla. La escala global de la enfermedad, la velocidad de su expansión, y la imposibilidad de los gobiernos (hasta ahora) de contenerla, así lo evidencian. Derechos internacionales y universales se confrontan en el campo de

\footnotetext{
2 José Saramago, Premio Nobel de Literatura 1998, escribe en 1995 Ensayo sobre la ceguera, novela que describe las consecuencias de una extraña epidemia que condena a la población de una ciudad a la ceguera y; en 2005 Las intermitencias de la muerte relata la desaparición de la muerte en un país y su impacto en las instituciones.

Estudios de la Paz y el Conflicto, Revista Latinoamericana, IUDPAS-UNAH, Volumen 1, Número 2, julio-diciembre 2020, pp. 150-161. DOI: $10.5377 /$ rlpc.v1i2.9838
} 
batalla de los gobiernos locales. Un futuro incierto, cuyo presente da cuenta de la amenaza de nuevos peligros en el horizonte lejano de una solidaridad global concertada.

\section{REFERENCIAS}

Beck, U. (2006). La sociedad del riesgo. Hacia una nueva modernidad. Barcelona: Paidós Surcos 25 .

Castel, R. (2013). "Políticas de riesgo y sentimiento de inseguridad". En Castel R., Kessler G., Merklen D. y Murard N. (Coords.). Individuación, precariedad, inseguridad ¿Des -institucionalización del presente?. Buenos Aires: Paidós.

De la Torre, M. (2010). Espacio público y capital social. Guanajuato: Consejo Editorial ULSB.

Fantini, C. (2020). El virus y el autoritarismo. El País, 27 de febrero. (Disponible en: https://www.elpais.com.uy/opinion/claudio-fantini/virus-autoritarismo.html)

Foucault, M. (2008). "Topologías" (trad. esp. Garcia, R.), Fractal n 48, enero-marzo, 2008, año XII, volumen XIII, 39-62.

Foucault, M. (2002). Vigilar y castigar. Nacimiento de la prisión (trad. esp. Garzón del Camino, A.). México: Siglo XIX.

García Canclini, N. (2001). Culturas hibridas. Estrategias para entrar y salir de la modernidad. Barcelona: Paidós.

Goffman, E. (1970). Estigma. La identidad deteriorada. (Disponible en: https://scholar.google.com/scholar?hl=es\&as_sdt=0\%2C5\&q=goffman+estigma $+\& b t$ $\underline{\mathrm{nG}=)}$

Harvey, D. (2017). El cosmopolitismo y las geografias de la libertad. México: Akai.

Jacobs J. (1961 trad. Esp. 1967). Muerte y vida de las grandes ciudades. Madrid: Península.

Kessler, G. (2009). El sentimiento de inseguridad. Sociología del temor al delito. Buenos Aires: Siglo XXI.

Luhmann, N. (1996). Confianza. México: Anthropos.

Thompson, J. (1998). Los medios y la modernidad. Una teoría de los medios de comunicación. Barcelona: Paidós.

\section{REFERENCIA DE LA AUTORA}

Marina Inés de la Torre es Doctora en Arquitectura por la Universidad de Guanajuato (2009). Profesora Titular B, de Tiempo Completo, del Departamento de Arquitectura, División de Arquitectura, Arte y Diseño, de la Universidad de Guanajuato. Nivel II en el Sistema Nacional de Investigadores. Responsable del Cuerpo Académico UGTO-CA146: Dinámicas Territoriales. Cuenta con numerosas publicaciones y colaboraciones en esta materia. Su línea principal de Investigación se centra en violencia, sociedad y territorio. Entre sus últimas publicaciones destacan: La ciudad neoliberal: conceptos y realidades de Dubái (2020). Nova Scientia No 24, Vol. 12 (1), 2020. ISSN 2007 - 0705, pp.: 1 - 33 doi.org/10.21640/ns.v12i24.2009; Espacio público y consumo en la ciudad central (2019). En Velasco Ávalos, M. y Navarrete D. Comercio tradicional y ciudades contemporáneas. Querétaro: Mandorla. 129-148; Gentrificación migratoria: San

Estudios de la Paz y el Conflicto, Revista Latinoamericana, IUDPAS-UNAH, Volumen 1, Número 2, julio-diciembre 2020, pp. 150-161. DOI: $10.5377 /$ rlpc.v1i2.9838 
Miguel de Allende, Guanajuato (2018). CULCYT - Cultura, Ciencia y Tecnología, Septiembre-Diciembre, 2018. Año 15, No 66, CULCyT $15^{\circ}$ Aniversario. Págs. 53-64, ISNN: 2007-0411, Universidad Autónoma de Ciudad Juárez, 2018. Disponible en: http://erevistas.uacj.mx/ojs/index.php/culcyt/article/view/2806; Turismo y narcotráfico en México (2018). Número Especial: Terror en el Paraíso: Terrorismo y Turismo en el Siglo XXI Estudios y Perspectivas en Turismo, ISSN: 1851-1732 (versión on-line), 03275841 (versión impresa), Volumen 27, Número 4, Págs. 867-882, Centro de Investigaciones y estudios turísticos (CIET), Buenos Aires, Octubre de 2018. Disponible en: http://www.estudiosenturismo.com.ar/. Buenos $\quad$ Aires, 2018. marinadlt8@hotmail.com. ORCID.0000-0001-7948-6979. 